\title{
THE DISPOSITION OF DISTANCE LEARNERS TOWARDS SUCCESS IN THEIR FIRST UNIVERSITY EXAMINATIONS AT THE WINNEBA STUDY CENTRE OF UNIVERSITY OF EDUCATION, WINNEBA, GHANA.
}

W. H. K. HORDZI

\begin{abstract}
The study was carried out to find out the disposition of 2006 level 100 distance education students of the Winneba Study Centre towards success in their first university examination. In all 100 students responded to items in a questionnaire. The results indicated that few days before the examination respondents had occasional memory loss and the phenomenon of forgetting easily (mean of 1.55). Also, the night before their first paper respondents had about six hours' sleep (mean of 2.11). In the course of writing the papers respondents read over the instructions thoroughly and carefully before attempting to answer the questions (mean of 2.88). In many cases the differences between the observed and expected frequencies were very highly significant.
\end{abstract}

KEY WORDS: Disposition, anxiety, stress, Winneba, examination, centre.

\section{INTRODUCTION}

One major thing which distinguishes educational programmes from informal learning activities is some kind of student evaluation schemes in the form of assignments and or tests. In most educational organizations, such assessment procedures provide means for awarding course grades as well as giving students feedback on their progress (Moore and Kearsley, 1996). In distance education, taking care to design ways of providing feedback and ensuring that instructors give regular feedback of good quality is of great importance because students are usually isolated and have limited opportunities for comparing their progress with others in the course (Moore and Kearsley, 1996). Furthermore, in distance education settings, testing presents some special challenges with respect to security. If students were to take examinations or quizzes at home or at a learning centre with no supervision, it would not be possible to ensure the integrity of the test. As a result, in most distance education programmes, students must complete their final examinations in a proctored setting at a learning centre or school. Proctors are usually teachers or administrators who are selected by the student and approved by the distance learning institution. Another procedure is to use computer-based testing in which each student receives a different subset of questions randomly selected by the computer. In many adult learning programmes, students complete a project report based on a research study instead of a final examination. While these alternative forms of testing and evaluation do not eliminate the possibility of a student cheating, they reduce it to a level of insignificance (Moore and Kearsley, 1996).

According to Jegede, Taylor, and Okebukola (1991), for most distance education classes, students' grading should be based upon such tools as regular assignments, individual or group projects, online or in-class quizzes, and take-home exams. These types of tests should have maximum validity, feasibility, and objectivity in order to meet the characteristics of all the students. However, University of Education, Winneba distance education students are mainly assessed through assignments and end of semester examinations. The assignments take the form of essays which students carry home to

W. H. K. Hordzi, Department of Educational Development and Extension, University of Education, Winneba P. O. Box 25, Winneba, Ghana 
do and hand over the scripts at their study centres on specific dates for marking. The assignment scores constitute $40 \%$ of the overall assessment mark in each course. Students do examination in each course at the end of the semester. The examinations are organized at the study centres under the strict supervision of the Centre Coordinators and invigilators. All students are given common questions which they see for the first time in the examination room. The examination score makes up $60 \%$ of the overall score for each course. Liu (1999) postulated that the assessment tools should be appropriate and include: filling in the blanks, multiple choice questions, identification of terms, a variety of short and essay questions for the students to select, and writing papers. In the case of University of Education, Winneba the examination questions are most often in the form of combination of objectives and essays. The assessment scores are used to measure what the students have learned and they also contribute to finding out the strengths and weaknesses of the students as well as grading for certification.

Just as it was identified by Wilson (1997), it was realized that at the Winneba Study Centre of the University of Education, Winneba the level 100 distance learning students of 2006 were of two specific groups. The first group was made up of adult learners who had been away from the school system for a long time. Their confidence was low. Their learning skills were rusty and they appeared to be unfit for a new style of learning. However, their motivation level seemed to be high. They had the will to learn, a desire to improve job or social standing, and possessed a craving for knowledge. The other group was younger school-aged students. They were used to daily supervision and guidance in a classroom setting. They had not developed the initial confidence or abilities as distance learners. Their self-concept appeared to be low or average but seemed to be more able to adapt to a new style of learning. These characteristics of the learners raised concern as to whether they could cope with their studies. The issue of what concerns especially in relation to their assessment also became a source of concern because it was vividly clear that a lot of the learners appeared jittery when they were given examination time table for their first examinations. Therefore, this study was initiated to find out the disposition of the 2006 level 100 distance education students of the Winneba Study Centre towards success in their first examination so that appropriate support services could be put in place to help them.

The main research question was "were the students full of anxiety and stress days before and during their first university examinations?" The specific objectives of the study were to find out:

- how the learners felt few days before their first examination

- how learners spent the night before their first examination

- $\quad$ the strategies that respondents used and how they fared during the examination

\section{METHODOLOGY}

The respondents were mainly 2006 year group level 100 students at the Winneba Study Centre of the University of Education, Winneba distance education programme. The total number of students at level 100 at the centre at the time was 419 . Out of that number 100 students were selected using simple random sampling when the students came for the last paper of their first university examinations.

The main instrument used was a questionnaire. The items were closed-ended types with three levels Likert-scale where respondents were simply expected to indicate whether the statement given was true (3), somehow true (2) or false (1). The items covered three broad areas, namely, how the learners felt few days before their first examination, how they spent the night before their first examination, and the strategies that they used and how they fared during the examination. The questionnaire was pilot tested on 25 students of the previous year group at level 100. Those items found to be inappropriate were either modified or completely removed. Copies of the questionnaire were given out to the 100 selected students to complete 30 minutes before the last paper of their first university examination started. The filled copies of the questionnaire were collected before the paper began. The results were collated and the rated mean for each item calculated. Standard deviations between the scores were also calculated. The differences between the observed and expected frequencies were also determined by using chi-square analysis.

\section{FINDINGS}

The respondents indicated that it was somehow true that they had sleepless nights, 
loss of appetite, neck and headaches, increased craving for stimulants (mean of 1.52); and occasional memory loss (Mean of 1.55). However, they responded false to all the other factors considered as problems before their first examination (mean less than 1.5). In all cases, the differences between the observed and expected frequencies were very highly significant $\left(X^{2} \geq 51.38 ; P=0.001\right)($ Table 1$)$

Table 1: Descriptive statistics of how respondents felt few days before their first examination

\begin{tabular}{llll}
\hline Response & $\begin{array}{l}\text { Rated } \\
\text { Mean }\end{array}$ & SD & $\mathbf{X}^{2}$ \\
\hline $\begin{array}{l}\text { I had sleepless nights, loss of appetite, neck and } \\
\text { headaches, increased craving for stimulants }\end{array}$ & 1.52 & 29.76 & 51.38 \\
I began to recollect earlier examination failures & 1.34 & 35.57 & 75.93 \\
I had occasional memory loss and forgetting easily & 1.55 & 22.81 & 31.22 \\
I was withdrawing from people/ unable to talk to people & 1.31 & 36.12 & 78.27 \\
$\begin{array}{l}\text { as usual } \\
\text { I found myself easily frightened by any negative }\end{array}$ & 1.40 & 32.15 & 62.0 \\
$\begin{array}{l}\text { feelings expressed about examinations by people } \\
\text { I had feelings of lack of hope }\end{array}$ & 43.25 & 112.23 \\
\hline $\mathrm{Df}=2 ; \quad$ tabulated $\mathrm{X}^{2}$ Value $=10.83(\mathrm{P}=0.001)$ & & \\
\hline
\end{tabular}

Key: $1-1.4=$ False; $1.5-2.4=$ Somehow true; $2.5-3.0=$ True

From table 2, respondents agreed that the night before their first examination they somehow studied for the greater part of the night (mean of 1.93); and had about six hours sleep (mean of 2.11); but did not perform their conjugal duties (mean of 1.24). The differences between the observed and expected frequencies for studying for the greater part of the night was not significant $\left(X^{2}=2.53 ; P=0.05\right)$ but highly significant for sleeping for about six hours $\left(X^{2}=\right.$ $10.15 ; P=0.01$ ) and very highly significant for performance of conjugal duties $\left(X^{2}=26.68 ; P\right.$ $=0.001)$.

Table 2: Descriptive statistics of how respondents spent the night before their first examination

\begin{tabular}{llll}
\hline Response & $\begin{array}{l}\text { Rated } \\
\text { Mean }\end{array}$ & SD & $\mathbf{X}^{2}$ \\
\hline I studied for the greater part of the night & 1.93 & 6.51 & 2.53 \\
I had about six hours sleep & 2.11 & 13.0 & 10.15 \\
I performed my conjugal duties & 1.24 & 19.08 & 26.68 \\
Df $=2$; tabulated $X^{2}$ Values $=3.84(\mathrm{P}=0.05) ; 6.64(\mathrm{P}=0.01) ; 10.83(\mathrm{P}=0.001)$ &
\end{tabular}

Key: $1-1.4=$ False; $1.5-2.4=$ Somehow true; $2.5-3.0=$ True

The statement "I was one of the first people to finish" scored a mean of 1.55 , while the statement "I found going over answers before handing over very boring" scored a mean of 2.18. Also, the statement "I double checked my answers before shading scored a mean of 2.64 while the statement "I read the instructions thoroughly and carefully before attempting to answer the questions" and "I tried to read the questions carefully to understand them fully before selecting them for answering" scored 2.88 each. Meanwhile, all the other statements scored means below 1.5. In all cases the differences between the observed and the expected frequencies were very highly significant $\left(X^{2} \geq\right.$ 18.04; $\mathrm{P}=0.001$ ) (Table 3). 
Table 3: Descriptive statistics of the strategies that respondents used and how they fared during the examination

\begin{tabular}{|c|c|c|c|}
\hline Response & $\begin{array}{l}\text { Rated } \\
\text { Mean }\end{array}$ & SD & $\mathbf{X}^{2}$ \\
\hline $\begin{array}{l}\text { I read the instructions thoroughly and carefully before attempting } \\
\text { to answer the questions }\end{array}$ & 2.88 & 50.81 & 154.90 \\
\hline $\begin{array}{l}\text { I tried to read the questions carefully to understand them fully } \\
\text { before selecting them for answering }\end{array}$ & 2.88 & 49.96 & 149.79 \\
\hline My brain just went blank and I could not think & 1.25 & 43.89 & 115.59 \\
\hline I found it very hard to concentrate & 1.28 & 36.90 & 81.19 \\
\hline I misunderstood most of the questions & 1.27 & 39.15 & 91.95 \\
\hline I was one of the first people to finish & 1.55 & 25.70 & 39.62 \\
\hline I used to bite my finger nails in the course of the examinations & 1.15 & 48.23 & 139.59 \\
\hline I double checked my answers before shading & 2.64 & 36.12 & 78.27 \\
\hline I found going over answers before handing over very boring & 2.18 & 17.50 & 18.04 \\
\hline $\begin{array}{l}\text { When I was not sure of answers I tried to get help from my } \\
\text { mates }\end{array}$ & 1.16 & 48.21 & 139.47 \\
\hline $\begin{array}{l}\text { My hands were shaking in the course of the examinations } \\
\qquad D f=2 ; \quad \text { tabulated } X^{2} \text { Value }=10.83(P=0.001)\end{array}$ & 1.30 & 39.58 & 93.99 \\
\hline
\end{tabular}

Key: 1-1.4 = False; $1.5-2.4=$ Somehow true; $2.5-3.0=$ True

\section{DISCUSSION}

According to White (1995), distance education students at the initial stages develop feelings of lack of preparedness and lack of confidence and a sense of inadequacy. While students with a lower self-esteem are those most likely to have difficulty with independent learning, they are also the group most apt to choose distance education courses out of false impressions that they are less demanding than classroom-based ones (Paul, 1990). In this study, the respondents indicated that it was somehow true that they had sleepless nights, loss of appetite, neck and headaches, increased craving for stimulants (1.52); and occasional memory loss and forgetting easily (1.55). These findings are showing that the respondents had some kind of examination related anxiety and stress. The findings are similar to the observation of Hinton and Casey (2008) that almost everyone feels nervous before an examination. Such nervousness goes with some kind of rumblings in the stomach and worrying thoughts such as "will I be able to answer the questions?, have I done enough revision?. Moore and Kearsley (1996) in a research on motivation of distance learners reported that some learners claimed that they were initially anxious and stressful. However, a certain amount of nervous tension is probably necessary for a student to perform to the best of his/her ability such that it produces a rush of adrenaline that helps the student to feel alert and focused. But too much anxiety can block thoughts, create a negative frame of mind, and lead to panic and potentially poor exam performance (Hinton and Casey, 2008). One of the inevitabilities of university life is examination. It is the opportunity of the student to demonstrate his/her new knowledge and to reap the rewards. There are two requirements for success. The first is knowing the content and the second is demonstrating that knowledge. Systematic use of these learning steps will not only insure learning, but it will also eliminate one of the most important causes of examination panic: the uncertainty concerning one's preparation. That is, it is necessary not only to know the course but to know that you know it. The self- testing provided by recitation and review is a rehearsal of the final act. It provides proof of preparation and a shield against panic. (Internet, http://www.stfx.ca/campus/stu-serv/disabledstudents/success/exam-strategies.html).

Most adult learners experience a considerable degree of anxiety about learning among which are anxieties about the ability to meet expectations. There is a considerable fear of failure, especially those distance learners who are less experience in the techniques of selflearning may have a high degree of anxiety at the beginning of the course (Moore and Kearsley, 1996). However, in this study respondents did not agree to the fact that they had feelings of lack of hope. This may be due to the fact that the learners might have quickly adjusted themselves into the mode of learning under distance education. Lum (2005) proposed that upgrading 
professional competencies principally concerns modifying learning behaviours and predispositions. Increasing the efficiency and effectiveness of flexible work-related learning and the development of new skills and knowledge are consistent with the goals of professional bridging education for adult learners who are attempting to adopt a different style of healthy practice.

Schunk (1991) considers the importance of self-concept and the belief or lack of belief in one's own ability as a major influence on student success. Those with a high sense of self-efficacy will work harder and persist longer when they experience difficulties. Perceived control, expectations and values, attributions and selfconcept are all influences of a person's selfefficacy. Those with low self-efficacy will not only do worse at tasks, they will also tend to avoid difficult ones altogether. In this study, respondents agreed that the night before their first examination they somehow studied for the greater part of the night (1.93); and had about six hours sleep (2.11); but did not perform their conjugal duties (1.24). Learning for most part of the night before examinations is not advisable. This is because one needs to have enough rest and reflect over what one has already learned. Gill, Willson, Kapoor, Rubenstein, Hayley, Viren, et al (Internet- http://www.ukstudent.net/modules/wfsection/article.php?

articled=103) recommended that on the day before the examination one can go to watch a movie or a play. One could even go to a fair. This works only if one has put in lots of work in advance. This tip works because the brain has created the necessary pathways to store and retrieve information that has been learned. One thing which is also important is that students need skills to handle various learning situations. This means a shift from content to skill development. Giving the student a system of strategies and help to develop the skills is a major step towards creating self-regulated learners (Lidner and Harris, 1993) who will not spend the whole night learning.

Having between six to eight hours' sleep the night before an examination can be considered as an ideal situation. Therefore, it can be considered as a normal situation when respondents indicated to some extent they spent about six hours in sleeping the night before the examination. Similarly, it can be considered as normal for learners to abstain from sex the night before the examination. This is because sex is very much energy consuming. Therefore, all self regulated learners will have their minds focused on their pending examination a night to the Dday. According to Zimmerman (1990) a selfregulated learner possesses the characteristics such as self-evaluation, organization and transformation, goal setting and planning, information seeking, record keeping, selfmonitoring, environment structuring, giving selfconsequences, rehearsing, memorizing, seeking social assistance, and reviewing. Such characteristics show how actively involved a selfregulated learner is. Such a learner does not complete work and then simply moves onto the next task. He/she consumes what he/she is involved with, learns it, knows it, waits for feedback and then if necessary revises or redoes it.

Since the statement "I was one of the first people to finish" scored a mean of 1.55 , while the statement "I found going over answers before handing over very boring" scored a mean of 2.18.then it can be said that respondents considered the statements somehow true. Similarly, since the statement "I double checked my answers before shading scored a mean of 2.64 while the statement "I read the instructions thoroughly and carefully before attempting to answer the questions" and "I tried to read the questions carefully to understand them fully before selecting them for answering" scored 2.88 each then respondents considered theses three statements to be true. Meanwhile, as all the other statements scored means below 1.5 then it means that they were considered to be false. It is very important for examination candidates to feel happy on the day of the examination and to think positively and keep cool in the course of the examination

(Internet, http://www.hypnosisdownloads.com/downloads/p hobias_fears/exams_nerves.html). Farrant (1964) also observes that an examination candidate needs to read and carefully, follow the instructions given by the examiner and as he/she does that it is important to underline key verbs in the questions so that he/she can be sure of what the examiner is looking for. Further, the candidate needs to plan a time table that allows time for reading through the paper, plan answers, check what has been written and allocate equal periods of time for each question to be answered. After all these the candidate needs to work to the time table in a disciplined way without panic (Farrant, 1964). Considering these facts then it may not be necessary for a student to rush through the solution to his/her examination 
questions in order to leave the room very early for the sake of it. Every bit of the time needs to be used profitably. After all, the examiner would not be so naive to give too much time for the paper such that students can easily finish within the shortest possible time and leave the room. If that happens, then the credibility and validity of the examination will be at stake.

Considering the responses in this study with regards to the submissions of Farrant (1964) it will be in the interest of a student to go over his/her answers to make sure mistakes are corrected before handing over the script to the invigilator. This is very important if petty mistakes that can mar the quality of the answers should be avoided. Furthermore, it is very important for examination candidates to read over the questions thoroughly to understand them and plan the answers before they begin to write. These would help the students or candidates to have some kind of control over what is being written and reduce the likelihood of writing so many irrelevant things.

There is nothing worse than after all your hard study you walk into your examination room and your mind goes blank. Your nerves and anxiety get the better of you and your brain simply stops working properly. This is a wellknown phenomenon in psychology - known as state-dependant memory. The state you are in determines what you can remember. If you are in a very unstable state of mind when you learn, it is hard to recall things (Internet, http://www.hypnosisdownloads.com/downloads/p hobias_fears/exams_nerves.html). Meanwhile, in this study respondents rejected the statements portraying that in the course of the examinations "their brains just went blank and they could not think", "they found it very hard to concentrate", or "they misunderstood most of the questions". In any case these answers can be considered in very positive terms such that it is an indication that the students were able to manage anxieties and stress associated with examinations especially with beginners.

\section{CONCLUSION}

To some extent respondents had sleepless nights, loss of appetite, neck and headaches, increased craving for stimulants; and occasional memory loss and forgetting. The over all indications are that the disposition of the respondents towards their first university examinations were mixed where to very limited cases they showed anxiety and stress while in other cases they did not. It can be said that by and large, respondents showed that they maintained their composure few days and the night before the examination. Also, the outcome of the research shows that generally, respondents adopted acceptable strategies in the course of the examination and did not exhibit serious negative traits. Hence, it can be concluded from the results that the respondents generally exhibited normal behaviour traits largely devoid of symptoms of stress and anxiety before and during their first university examinations.

\section{RECOMMENDATIONS}

Though, not all the respondents developed examination related anxiety, stress, loss of appetite, neck and headaches, increased craving for stimulants and occasional memory loss and forgetting easily there is the need for the Winneba Study Centre Coordinator, the tutors and with Support from the university put in place more comprehensive orientation programme for newly admitted students on the university's examination rules and conditions. The centre also needs to organize occasional counselling services for students to minimize their fears about examination failure.

\section{REFERENCES}

Farrant, J. S., 1964. Principles and Practices of Education, New Edition. London: Burnt Mill:

Gill, B., Willson, N. , Kapoor, L., Rubenstein, B., Hayley K., Viren, T., Vivek R, Anonymous, Derouin, T. and Sondra, C. (Internet) how to beat examination stress http://www.uk-

student.net/modules/wfsection/article.php ?articleid=103

Hinton, A. and Casey, M., 2008. Managing Exam Anxiety and Panic: A Guide for Students. Directorate of Academic and Student Affairs. http://owww.brookes.ac.uk/student/se rvic es/health/exam.html

Internet - Exam Strategies: Learning and Study Techniques - 
http://www.stfx.ca/campus/stuserv/diabled-students/success/examstrategies.html Retrieved 31/10/08

Internet - Overcome exam nerves and improve your studying, memory and recall http://www.hypnosisdownloads.com/d ownloads/phobia fears/exams_nerves.html.Retrieved $\overline{3} 1 / 10 / 08$

Jegede, O. J., Taylor, J. C., and Okebukola, P. A., 1991. Knowledge engineering: An alternative approach to curriculum design for science education at a distance. Research in_Higher Education, 21: 198207.

Lidner, R.W. and Harris, B.R., 1993. Teaching self-regulated learning strategies. In M.R. Simonson and K. Abu-Omar (Eds.). Proceedings of Selected Research and Development Presentations at the 1993 National Convention of the Association for Educational Communications and Technology, New Orleans, LA. Ames, IA: AECT, 641-654.

Liu, Y., 1999. Cognitive Styles and Distance Education. Online Journal of Distance Learning Administration, 2, (3): 903
Lum, L.., 2005. Internationally-educated health professionals: a distance education multiple cultures model. Education \& Training 48, (2/3): 112-126

Paul, R. (1990). Towards a new measure of success: developing independent learners. Open Learning 5(1): 31-38.

Moore, M. G. and Kearsley, G., 1996. Distance Education: A Systems View. Belmont: Wadsworth publishing Company

Schunk, D.H., 1991. Self-efficacy and academic motivation. Educational Psychologist, 26: 207-231.

White, C., 1995. Autonomy and strategy use in distance foreign language learning. System 23, (2): 207-221.

Wilson, J., 1997. Self Regulated Learners and Distance Education Theory. http://www.usak.ca/education/course work/802papers/wilson/wilson.html Retrieved 31/10/08

Zimmerman, B. J., 1990. Self-regulated learning and academic achievement: An Overview. Educational Psychologist, 25: 3-17. 